1 Hacettepe Journal of Mathematics and Statistics

Volume 43 (2) (2014), 209-225

\title{
Convergence to common fixed points of multi-step iteration process for generalized asymptotically quasi-nonexpansive mappings in convex metric spaces
}

\author{
G. S. Saluja*
}

\begin{abstract}
In this paper, we study strong convergence of multi-step iterations with errors for a finite family of generalized asymptotically quasinonexpansive mappings in the framework of convex metric spaces. The new iteration scheme includes modified Mann and Ishikawa iterations with errors, the three-step iteration scheme of $\mathrm{Xu}$ and Noor as special cases in Banach spaces. Our results extend and generalize many known results from the current literature.
\end{abstract}

Keywords: Generalized asymptotically quasi-nonexpansive mapping, multi-step iterations with errors, common fixed point, strong convergence, convex metric

2000 AMS Classification: 47H09, 47H10.

\section{Introduction and Preliminaries}

Let $T$ be a self map on a nonempty subset $C$ of a metric space $(X, d)$. Denote the set of fixed points of $T$ by $F(T)=\{x \in C: T(x)=x\}$. We say that $T$ is:

(1) nonexpansive if

$$
d(T x, T y) \leq d(x, y)
$$

for all $x, y \in C$;

(2) quasi-nonexpansive if $F(T) \neq \emptyset$ and

$$
d(T x, p) \leq d(x, p)
$$

for all $x \in C$ and $p \in F(T)$;

*Department of Mathematics and Information Technology, Govt. Nagarjuna P.G. College of Science, Raipur - 492010 (C.G.), India, Email: saluja_1963@rediffmail.com, saluja1963@gmail.com 
(3) asymptotically nonexpansive [5] if there exists a sequence $\left\{r_{n}\right\} \subset[0, \infty)$ with $\lim _{n \rightarrow \infty} r_{n}=0$ such that

$$
d\left(T^{n} x, T^{n} y\right) \leq\left(1+r_{n}\right) d(x, y)
$$

for all $x, y \in C$ and $n \geq 1$;

(4) asymptotically quasi-nonexpansive if $F(T) \neq \emptyset$ and there exists a sequence $\left\{r_{n}\right\} \subset[0, \infty)$ with $\lim _{n \rightarrow \infty} r_{n}=0$ such that

$$
d\left(T^{n} x, p\right) \leq\left(1+r_{n}\right) d(x, p)
$$

for all $x \in C, p \in F(T)$ and $n \geq 1$;

(5) generalized asymptotically quasi-nonexpansive [6] if $F(T) \neq \emptyset$ and there exist two sequences of real numbers $\left\{r_{n}\right\},\left\{s_{n}\right\} \subset[0, \infty)$ with $\lim _{n \rightarrow \infty} r_{n}=0=$ $\lim _{n \rightarrow \infty} s_{n}$ such that

$$
d\left(T^{n} x, p\right) \leq\left(1+r_{n}\right) d(x, p)+s_{n},
$$

for all $x \in C, p \in F(T)$ and $n \geq 1$;

(6) uniformly $L$-Lipschitzian if there exists a constant $L>0$ such that

$$
d\left(T^{n} x, T^{n} y\right) \leq L d(x, y)
$$

for all $x, y \in C$ and $n \geq 1$;

(7) semi-compact if for any bounded sequence $\left\{x_{n}\right\}$ in $C$ with $d\left(x_{n}, T x_{n}\right) \rightarrow 0$ as $n \rightarrow \infty$, there is a convergent subsequence of $\left\{x_{n}\right\}$.

Let $\left\{x_{n}\right\}$ be a sequence in a metric space $(X, d)$, and let $C$ be a subset of $X$. We say that $\left\{x_{n}\right\}$ is:

(8) of monotone type [22] with respect to $C$ if for each $p \in C$, there exist two sequences $\left\{a_{n}\right\}$ and $\left\{b_{n}\right\}$ of nonnegative real numbers such that $\sum_{n=1}^{\infty} a_{n}<\infty$, $\sum_{n=1}^{\infty} b_{n}<\infty$ and

$$
d\left(x_{n+1}, p\right) \leq\left(1+a_{n}\right) d\left(x_{n}, p\right)+b_{n} .
$$

1.1. Remark. (1) It is clear that the nonexpansive mappings with the nonempty fixed point set $F(T)$ are quasi-nonexpansive.

(2) The linear quasi-nonexpansive mappings are nonexpansive, but it is easily seen that there exist nonlinear continuous quasi-nonexpansive mappings which are not nonexpansive; for example, define $T(x)=(x / 2) \sin (1 / x)$ for all $x \neq 0$ and 
$T(0)=0$ in $\mathbb{R}$

(3) It is obvious that if $T$ is nonexpansive, then it is asymptotically nonexpansive with the constant sequence $\{1\}$.

(4) If $T$ is asymptotically nonexpansive, then it is uniformly Lipschitzian with the uniform Lipschitz constant $L=\sup \left\{1+r_{n}: n \geq 1\right\}$. However, the converse of this claim is not true.

(5) If in definition (5), $s_{n}=0$ for all $n \geq 1$, then $T$ becomes asymptotically quasi-nonexpansive, and hence the class of generalized asymptotically quasinonexpansive maps includes the class of asymptotically quasi-nonexpansive maps.

In 1991, Schu $[16,17]$ introduced the following iterative scheme: let $X$ be a normed linear space, let $C$ be a nonempty convex subset of $X$, and let $T: C \rightarrow C$ be a given mapping. Then, for arbitrary $x_{1} \in C$, the modified Ishikawa iterative scheme $\left\{x_{n}\right\}$ is defined by

$$
\begin{aligned}
y_{n} & =\left(1-\beta_{n}\right) x_{n}+\beta_{n} T^{n} x_{n} \\
x_{n+1} & =\left(1-\alpha_{n}\right) x_{n}+\alpha_{n} T^{n} y_{n}, \quad n \geq 1,
\end{aligned}
$$

where $\left\{\alpha_{n}\right\}$ and $\left\{\beta_{n}\right\}$ are some suitable sequences $[0,1]$. With $X, C,\left\{\alpha_{n}\right\}$, and $x_{1}$ as above, the modified Mann iterative scheme $\left\{x_{n}\right\}$ is defined by

$$
x_{1} \in C,
$$

$$
x_{n+1}=\left(1-\alpha_{n}\right) x_{n}+\alpha_{n} T^{n} x_{n}, n \geq 1 .
$$

In 1998, Xu [21] introduced the following iterative scheme: let $X$ be a normed linear space, let $C$ be a nonempty convex subset of $X$, and let $T: C \rightarrow C$ be a given mapping. Then, for arbitrary $x_{1} \in C$, the Ishikawa iterative scheme $\left\{x_{n}\right\}$ with errors is defined by

$$
\begin{aligned}
y_{n} & =\overline{a_{n}} x_{n}+\overline{b_{n}} T x_{n}+\overline{c_{n}} v_{n} \\
x_{n+1} & =\overline{a_{n}} x_{n}+b_{n} T y_{n}+c_{n} u_{n}, n \geq 1,
\end{aligned}
$$

where $\left\{u_{n}\right\},\left\{v_{n}\right\}$ are bounded sequences in $C$ and $\left\{a_{n}\right\},\left\{b_{n}\right\},\left\{c_{n}\right\},\left\{\overline{a_{n}}\right\},\left\{\overline{b_{n}}\right\}$, $\left\{\overline{c_{n}}\right\}$ are sequences $[0,1]$ with $a_{n}+b_{n}+c_{n}=\overline{a_{n}}+\overline{b_{n}}+\overline{c_{n}}=1$. With $X, C,\left\{u_{n}\right\}$, $\left\{a_{n}\right\},\left\{b_{n}\right\},\left\{c_{n}\right\}$, and $x_{1}$ as above, the Mann iterative scheme $\left\{x_{n}\right\}$ with errors is defined by

$$
x_{1} \in C,
$$

$$
x_{n+1}=a_{n} x_{n}+b_{n} T x_{n}+c_{n} u_{n}, \quad n \geq 1 .
$$

Based on the iterative scheme with errors introduced by $\mathrm{Xu}$ [21], the following iteration schemes have been used and studied by several authors (see [1, 3, 12]). 
Let $X$ be a normed linear space, let $C$ be a nonempty convex subset of $X$, and let $T: C \rightarrow C$ be a given mapping. Then, for arbitrary $x_{1} \in C$, the modified Ishikawa iteration scheme $\left\{x_{n}\right\}$ with errors is defined by

$$
\begin{aligned}
& y_{n}=\overline{a_{n}} x_{n}+\overline{b_{n}} T^{n} x_{n}+\overline{c_{n}} v_{n} \\
& x_{n+1}=a_{n} x_{n}+b_{n} T^{n} y_{n}+c_{n} u_{n}, n \geq 1,
\end{aligned}
$$

where $\left\{u_{n}\right\},\left\{v_{n}\right\}$ are bounded sequences in $C$ and $\left\{a_{n}\right\},\left\{b_{n}\right\},\left\{c_{n}\right\},\left\{\overline{a_{n}}\right\},\left\{\overline{b_{n}}\right\}$, $\left\{\overline{c_{n}}\right\}$ are sequences $[0,1]$ with $a_{n}+b_{n}+c_{n}=\overline{a_{n}}+\overline{b_{n}}+\overline{c_{n}}=1$. With $X, C,\left\{u_{n}\right\}$, $\left\{a_{n}\right\},\left\{b_{n}\right\},\left\{c_{n}\right\}$, and $x_{1}$ as above, the modified Mann iteration scheme $\left\{x_{n}\right\}$ with errors is defined by

$$
x_{1} \in C,
$$

$$
x_{n+1}=a_{n} x_{n}+b_{n} T^{n} x_{n}+c_{n} u_{n}, n \geq 1 .
$$

Recently, Imnang and Suantai [6] studied multi-step Noor iterations with errors for a finite family of generalized asymptotically quasi-nonexpansive mappings and established some strong convergence theorems in the framework of uniformly convex Banach spaces. The scheme of [6] is as follows: Let $T_{i}: C \rightarrow C(i=1,2, \ldots, k)$ be mappings and $F=\bigcap_{i=1}^{k} F\left(T_{i}\right)$. For a given $x_{1} \in C$, and a fixed $k \in \mathbb{N}$ ( $\mathbb{N}$ denote the set of all positive integers), compute the iterative sequences $\left\{x_{n}\right\}$ and $\left\{y_{\text {in }}\right\}$ by

$$
\begin{aligned}
x_{n+1} & =y_{k n}=\alpha_{k n} T_{k}^{n} y_{(k-1) n}+\beta_{k n} x_{n}+\gamma_{k n} u_{k n}, \\
y_{(r-1) n} & =\alpha_{(k-1) n} T_{k-1}^{n} y_{(k-2) n}+\beta_{(k-1) n} x_{n}+\gamma_{(k-1) n} u_{(k-1) n}, \\
\vdots & \\
y_{3 n} & =\alpha_{3 n} T_{3}^{n} y_{2 n}+\beta_{3 n} x_{n}+\gamma_{3 n} u_{3 n}, \\
y_{2 n} & =\alpha_{2 n} T_{2}^{n} y_{1 n}+\beta_{2 n} x_{n}+\gamma_{2 n} u_{2 n}, \\
y_{1 n} & =\alpha_{1 n} T_{1}^{n} y_{0 n}+\beta_{1 n} x_{n}+\gamma_{1 n} u_{1 n}, \quad n \geq 1 .
\end{aligned}
$$

where $y_{0 n}=x_{n}$ and $\left\{u_{1 n}\right\},\left\{u_{2 n}\right\}, \ldots,\left\{u_{k n}\right\}$ are bounded sequences in $C$ with $\left\{\alpha_{i n}\right\},\left\{\beta_{i n}\right\}$, and $\left\{\gamma_{i n}\right\}$ are appropriate real sequences in $[0,1]$ such that $\alpha_{i n}+$ $\beta_{i n}+\gamma_{i n}=1$ for all $i=1,2, \ldots, k$ and all $n$. This iteration scheme includes the modified Mann iteration scheme (1.12), the modified Ishikawa iteration scheme (1.11) and extends the three-step iteration by $\mathrm{Xu}$ and Noor [20].

One of the most interesting aspects of metric fixed point theory is to extend a linear version of a known result to the nonlinear case in metric spaces. To achieve this, Takahashi [18] introduced a convex structure in a metric space $(X, d)$ and the properties of the space.

1.2. Definition. Let $(X, d)$ be a metric space and $I=[0,1]$. A mapping $W: X^{3} \times$ $I^{3} \rightarrow X$ is said to be a convex structure on $X$ if it satisfies the following condition:

$$
d(u, W(x, y, z ; \alpha, \beta, \gamma)) \leq \alpha d(u, x)+\beta d(u, y)+\gamma d(u, z),
$$


for any $u, x, y, z \in X$ and for any $\alpha, \beta, \gamma \in I$ with $\alpha+\beta+\gamma=1$.

If $(X, d)$ is a metric space with a convex structure $W$, then $(X, d)$ is called a convex metric space and denotes it by $(X, d, W)$.

1.3. Remark. It is easy to prove that every linear normed space is a convex metric space with a convex structure $W(x, y, z ; \alpha, \beta, \gamma)=\alpha x+\beta y+\gamma z$, for all $x, y, z \in X$ and $\alpha, \beta, \gamma \in I$ with $\alpha+\beta+\gamma=1$. But there exist some convex metric spaces which can not be embedded into any linear normed spaces (see, Takahashi $[18])$.

1.4. Example. Let $X=\left\{\left(x_{1}, x_{2}, x_{3}\right) \in \mathbb{R}^{3}: x_{1}>0, x_{2}>0, x_{3}>0\right\}$. For $x=\left(x_{1}, x_{2}, x_{3}\right), y=\left(y_{1}, y_{2}, y_{3}\right) \in X$ and $\alpha, \beta, \gamma \in I$ with $\alpha+\beta+\gamma=1$, we define a mapping $W: X^{3} \times I^{3} \rightarrow X$ by

$$
W(x, y, z ; \alpha, \beta, \gamma)=\left(\alpha x_{1}+\beta y_{1}+\gamma z_{1}, \alpha x_{2}+\beta y_{2}+\gamma z_{2}, \alpha x_{3}+\beta y_{3}+\gamma z_{3}\right)
$$

and define a metric $d: X \times X \rightarrow[0, \infty)$ by

$$
d(x, y)=\left|x_{1} y_{1}+x_{2} y_{2}+x_{3} y_{3}\right| .
$$

Then we can show that $(X, d, W)$ is a convex metric space, but it is not a normed space.

Denote the indexing set $\{1,2, \ldots, k\}$ by $I$. We now translate the scheme (1.13) from the normed space setting to the more general setup of convex metric space as follows:

$$
x_{1} \in C, \quad x_{n+1}=U_{n(k)} x_{n}, \quad n \geq 1,
$$

where

$$
\begin{aligned}
U_{n(0)} & =I, \text { the identity map, } \\
U_{n(1)} x & =W\left(T_{1}^{n} U_{n(0)} x, x, u_{n(1)} ; \alpha_{n(1)}, \beta_{n(1)}, \gamma_{n(1)}\right), \\
U_{n(2)} x & =W\left(T_{2}^{n} U_{n(1)} x, x, u_{n(2)} ; \alpha_{n(2)}, \beta_{n(2)}, \gamma_{n(2)}\right), \\
\vdots & \\
U_{n(k-1)} x & =W\left(T_{k-1}^{n} U_{n(k-2)} x, x, u_{n(k-1)} ; \alpha_{n(k-1)}, \beta_{n(k-1)}, \gamma_{n(k-1)}\right), \\
U_{n(k)} x & =W\left(T_{k}^{n} U_{n(k-1)} x, x, u_{n(k)} ; \alpha_{n(k)}, \beta_{n(k)}, \gamma_{n(k)}\right), \quad n \geq 1,
\end{aligned}
$$

where $\left\{u_{n(1)}\right\},\left\{u_{n(2)}\right\}, \ldots,\left\{u_{n(k)}\right\}$ are bounded sequences in $C$ with $\left\{\alpha_{n(i)}\right\},\left\{\beta_{n(i)}\right\}$, and $\left\{\gamma_{n(i)}\right\}$ are appropriate real sequences in $[0,1]$ such that $\alpha_{n(i)}+\beta_{n(i)}+\gamma_{n(i)}=1$ for all $i \in I$ and all $n$. 
In a convex metric space, the scheme (1.14) provides analogues of:

(i) the scheme (1.12) if $k=1$ and $T_{1}=T$;

(ii) the scheme (1.11) if $k=2$ and $T_{1}=T_{2}=T$.

This scheme becomes the scheme (1.13) if we choose a special convex metric space, namely, a normed space.

In this paper, we establish strong convergence theorem for the iteration scheme (1.14) to converge to common fixed point of a finite family of generalized asymptotically quasi-nonexpansive mappings in the framework of convex metric spaces. Our result extends and as well as refines the corresponding results of [2], [4], [6][17], [20] and many others.

We need the following useful lemma to prove our convergence results.

1.5. Lemma. (see [19]) Let $\left\{p_{n}\right\},\left\{q_{n}\right\},\left\{r_{n}\right\}$ be three sequences of nonnegative real numbers satisfying the following conditions:

$$
p_{n+1} \leq\left(1+q_{n}\right) p_{n}+r_{n}, \quad n \geq 0, \quad \sum_{n=0}^{\infty} q_{n}<\infty, \quad \sum_{n=0}^{\infty} r_{n}<\infty .
$$

Then

(1) $\lim _{n \rightarrow \infty} p_{n}$ exists.

(2) In addition, if $\liminf _{n \rightarrow \infty} p_{n}=0$, then $\lim _{n \rightarrow \infty} p_{n}=0$.

\section{Main Results}

In this section, we prove strong convergence theorems of multi-step iteration scheme (1.14) for a finite family of generalized asymptotically quasi-nonexpansive mappings in convex metric spaces.

2.1. Lemma. Let $(X, d)$ be a complete convex metric space, and let $C$ be a nonempty closed convex subset of $X$. Let $\left\{T_{i}: i \in I\right\}$ be a finite family of generalized asymptotically quasi-nonexpansive self-maps on $C$ with sequences $\left\{r_{n(i)}\right\},\left\{s_{n(i)}\right\} \subset$ $[0, \infty)$ for each $i \in I$, respectively, such that $\sum_{n=1}^{\infty} r_{n(i)}<\infty$ and $\sum_{n=1}^{\infty} s_{n(i)}<\infty$. Assume that $F=\cap_{i=1}^{k} F\left(T_{i}\right)$ is a nonempty set. Let $\left\{x_{n}\right\}$ be the multi-step iteration scheme defined by (1.14) with $\sum_{n=1}^{\infty} \gamma_{n(i)}<\infty$ for each $i \in I$. Then

(i)

$$
d\left(x_{n+1}, p\right) \leq\left(1+B_{n(k)}\right) d\left(x_{n}, p\right)+A_{n(k)},
$$

with $\sum_{n=1}^{\infty} B_{n(k)}<\infty$ and $\sum_{n=1}^{\infty} A_{n(k)}<\infty$. 
(ii)

$$
d\left(x_{n+m}, p\right) \leq Q d\left(x_{n}, p\right)+Q \sum_{j=n}^{n+m-1} A_{j(k)},
$$

for $m \geq 1, n \geq 1, p \in F$ and for some $Q>0$.

Proof. (i) For any $p \in F$, from (1.14), we have

$$
\begin{aligned}
d\left(U_{n(1)} x_{n}, p\right) & =d\left(W\left(T_{1}^{n} x_{n}, x_{n}, u_{n(1)} ; \alpha_{n(1)}, \beta_{n(1)}, \gamma_{n(1)}\right), p\right) \\
& \leq \alpha_{n(1)} d\left(T_{1}^{n} x_{n}, p\right)+\beta_{n(1)} d\left(x_{n}, p\right)+\gamma_{n(1)} d\left(u_{n(1)}, p\right) \\
& \leq \alpha_{n(1)}\left[\left(1+r_{n(1)}\right) d\left(x_{n}, p\right)+s_{n(1)}\right]+\beta_{n(1)} d\left(x_{n}, p\right)+\gamma_{n(1)} d\left(u_{n(1)}, p\right) \\
& \leq\left[\alpha_{n(1)}+\beta_{n(1)}\right]\left(1+r_{n(1)}\right) d\left(x_{n}, p\right)+\alpha_{n(1)} s_{n(1)}+\gamma_{n(1)} d\left(u_{n(1)}, p\right) \\
& =\left[1-\gamma_{n(1)}\right]\left(1+r_{n(1)}\right) d\left(x_{n}, p\right)+A_{n(1)} \\
(2.1) & \leq\left(1+r_{n(1)}\right) d\left(x_{n}, p\right)+A_{n(1)},
\end{aligned}
$$

where $A_{n(1)}=\alpha_{n(1)} s_{n(1)}+\gamma_{n(1)} d\left(u_{n(1)}, p\right)$, since by assumption $\sum_{n=1}^{\infty} s_{n(1)}<\infty$ and $\sum_{n=1}^{\infty} \gamma_{n(1)}<\infty$, it follows that $\sum_{n=1}^{\infty} A_{n(1)}<\infty$.

Again from (1.14) and using (2.1), we have

$$
\begin{aligned}
d\left(U_{n(2)} x_{n}, p\right)= & d\left(W\left(T_{2}^{n} U_{n(1)} x_{n}, x_{n}, u_{n(2)} ; \alpha_{n(2)}, \beta_{n(2)}, \gamma_{n(2)}\right), p\right) \\
\leq & \alpha_{n(2)} d\left(T_{2}^{n} U_{n(1)} x_{n}, p\right)+\beta_{n(2)} d\left(x_{n}, p\right)+\gamma_{n(2)} d\left(u_{n(2)}, p\right) \\
\leq & \alpha_{n(2)}\left[\left(1+r_{n(2)}\right) d\left(U_{n(1)} x_{n}, p\right)+s_{n(2)}\right]+\beta_{n(2)} d\left(x_{n}, p\right)+\gamma_{n(2)} d\left(u_{n(2)}, p\right) \\
\leq & \alpha_{n(2)}\left(1+r_{n(2)}\right)\left[\left(1+r_{n(1)}\right) d\left(x_{n}, p\right)+A_{n(1)}\right]+\alpha_{n(2)} s_{n(2)}+\beta_{n(2)} d\left(x_{n}, p\right) \\
& +\gamma_{n(2)} d\left(u_{n(2)}, p\right) \\
\leq & {\left[\alpha_{n(2)}+\beta_{n(2)}\right]\left(1+r_{n(1)}\right)\left(1+r_{n(2)}\right) d\left(x_{n}, p\right)+\alpha_{n(2)}\left(1+r_{n(2)}\right) A_{n(1)} } \\
& +\alpha_{n(2)} s_{n(2)}+\beta_{n(2)} d\left(x_{n}, p\right)+\gamma_{n(2)} d\left(u_{n(2)}, p\right) \\
= & {\left[1-\gamma_{n(2)}\right]\left(1+r_{n(1)}+r_{n(2)}+r_{n(1)} r_{n(2)}\right) d\left(x_{n}, p\right)+\alpha_{n(2)}\left(1+r_{n(2)}\right) A_{n(1)} } \\
& +\alpha_{n(2)} s_{n(2)}+\gamma_{n(2)} d\left(u_{n(2)}, p\right) \\
(2.2) \leq & \left(1+B_{n(2)}\right) d\left(x_{n}, p\right)+A_{n(2)},
\end{aligned}
$$

where $B_{n(2)}=r_{n(1)}+r_{n(2)}+r_{n(1)} r_{n(2)}$ and $A_{n(2)}=\alpha_{n(2)}\left(1+r_{n(2)}\right) A_{n(1)}+$ $\alpha_{n(2)} s_{n(2)}+\gamma_{n(2)} d\left(u_{n(2)}, p\right)$, since by assumptions $\sum_{n=1}^{\infty} r_{n(1)}<\infty, \sum_{n=1}^{\infty} r_{n(2)}$ $<\infty, \sum_{n=1}^{\infty} s_{n(2)}<\infty, \sum_{n=1}^{\infty} A_{n(1)}<\infty$ and $\sum_{n=1}^{\infty} \gamma_{n(2)}<\infty$, it follows that $\sum_{n=1}^{\infty} B_{n(2)}<\infty$ and $\sum_{n=1}^{\infty} A_{n(2)}<\infty$. 
Further using (1.14) and (2.2), we have

$$
\begin{aligned}
d\left(U_{n(3)} x_{n}, p\right)= & d\left(W\left(T_{3}^{n} U_{n(2)} x_{n}, x_{n}, u_{n(3)} ; \alpha_{n(3)}, \beta_{n(3)}, \gamma_{n(3)}\right), p\right) \\
\leq & \alpha_{n(3)} d\left(T_{3}^{n} U_{n(2)} x_{n}, p\right)+\beta_{n(3)} d\left(x_{n}, p\right)+\gamma_{n(3)} d\left(u_{n(3)}, p\right) \\
\leq & \alpha_{n(3)}\left[\left(1+r_{n(3)}\right) d\left(U_{n(2)} x_{n}, p\right)+s_{n(3)}\right]+\beta_{n(3)} d\left(x_{n}, p\right)+\gamma_{n(3)} d\left(u_{n(3)}, p\right) \\
\leq & \alpha_{n(3)}\left(1+r_{n(3)}\right)\left[\left(1+B_{n(2)}\right) d\left(x_{n}, p\right)+A_{n(2)}\right]+\alpha_{n(3)} s_{n(3)}+\beta_{n(3)} d\left(x_{n}, p\right) \\
& +\gamma_{n(3)} d\left(u_{n(3)}, p\right) \\
\leq & {\left[\alpha_{n(3)}+\beta_{n(3)}\right]\left(1+r_{n(3)}\right)\left(1+B_{n(2)}\right) d\left(x_{n}, p\right)+\alpha_{n(3)}\left(1+r_{n(3)}\right) A_{n(2)} } \\
& +\alpha_{n(3)} s_{n(3)}+\beta_{n(3)} d\left(x_{n}, p\right)+\gamma_{n(3)} d\left(u_{n(3)}, p\right) \\
= & {\left.\left[1-\gamma_{n(3)}\right]\left(1+r_{n(3)}+B_{n(2)}+r_{n(3)} B_{n(2)}\right) d\left(x_{n}, p\right)+\alpha_{n(3)}\left(1+r_{n(3)}\right) A_{n(2)}\right) } \\
& +\alpha_{n(3)} s_{n(3)}+\gamma_{n(3)} d\left(u_{n(3)}, p\right) \\
(2.3) \leq & \left(1+B_{n(3)}\right) d\left(x_{n}, p\right)+A_{n(3)},
\end{aligned}
$$

where $B_{n(3)}=r_{n(3)}+B_{n(2)}+r_{n(3)} B_{n(2)}$ and $A_{n(3)}=\alpha_{n(3)}\left(1+r_{n(3)}\right) A_{n(2)}+$ $\alpha_{n(3)} s_{n(3)}+\gamma_{n(3)} d\left(u_{n(3)}, p\right)$, since by assumptions $\sum_{n=1}^{\infty} r_{n(3)}<\infty, \sum_{n=1}^{\infty} B_{n(2)}$ $<\infty, \sum_{n=1}^{\infty} s_{n(3)}<\infty, \sum_{n=1}^{\infty} A_{n(2)}<\infty$ and $\sum_{n=1}^{\infty} \gamma_{n(3)}<\infty$, it follows that $\sum_{n=1}^{\infty} B_{n(3)}<\infty$ and $\sum_{n=1}^{\infty} A_{n(3)}<\infty$. Continuing in this process, we get

$$
d\left(x_{n+1}, p\right) \leq\left(1+B_{n(k)}\right) d\left(x_{n}, p\right)+A_{n(k)},
$$

where $B_{n(k)}=r_{n(k)}+B_{n(k-1)}+r_{n(k)} B_{n(k-1)}$ and $A_{n(k)}=\alpha_{n(k)}\left(1+r_{n(k)}\right) A_{n(k-1)}+$ $\alpha_{n(k)} s_{n(k)}+\gamma_{n(k)} d\left(u_{n(k)}, p\right)$ with $\sum_{n=1}^{\infty} B_{n(k)}<\infty$ and $\sum_{n=1}^{\infty} A_{n(k)}<\infty$.

The conclusion (i) holds.

(ii) Note that when $x>0,1+x \leq e^{x}$. It follows from conclusion (i) that for $m \geq 1, n \geq 1$ and $p \in F$, we have 


$$
\begin{aligned}
& d\left(x_{n+m}, p\right) \leq\left(1+B_{n+m-1(k)}\right) d\left(x_{n+m-1}, p\right)+A_{n+m-1(k)} \\
& \leq e^{B_{n+m-1(k)}} d\left(x_{n+m-1}, p\right)+A_{n+m-1(k)} \\
& \leq e^{B_{n+m-1(k)}}\left[e^{B_{n+m-2(k)}} d\left(x_{n+m-2}, p\right)+A_{n+m-2(k)}\right] \\
& +A_{n+m-1(k)} \\
& \leq e^{\left\{B_{n+m-1(k)}+B_{n+m-2(k)}\right\}} d\left(x_{n+m-2}, p\right) \\
& +e^{B_{n+m-1(k)}}\left[A_{n+m-2(k)}+A_{n+m-1(k)}\right] \\
& \leq \ldots \\
& \leq\left\{e^{\sum_{j=n}^{n+m-1} B_{j(k)}}\right\} d\left(x_{n}, p\right)+\left\{e^{\sum_{j=n+1}^{n+m-1} B_{j(k)}}\right\}\left(\sum_{j=n}^{n+m-1} A_{j(k)}\right) \\
& \leq\left\{e^{\sum_{j=n}^{n+m-1} B_{j(k)}}\right\} d\left(x_{n}, p\right)+\left\{e^{\sum_{j=n}^{n+m-1} B_{j(k)}}\right\}\left(\sum_{j=n}^{n+m-1} A_{j(k)}\right) .
\end{aligned}
$$

Let $Q=e^{\sum_{j=n}^{n+m-1} B_{j(k)}}$. Then $0<Q<\infty$ and

$$
d\left(x_{n+m}, p\right) \leq Q d\left(x_{n}, p\right)+Q\left(\sum_{j=n}^{n+m-1} A_{j(k)}\right) .
$$

Thus, the conclusion (ii) holds.

We now state and prove the main theorem of this section.

2.2. Theorem. Let $(X, d)$ be a complete convex metric space, and let $C$ be a nonempty closed convex subset of $X$. Let $\left\{T_{i}: i \in I\right\}$ be a finite family of generalized asymptotically quasi-nonexpansive self-maps on $C$ with sequences $\left\{r_{n(i)}\right\},\left\{s_{n(i)}\right\} \subset[0, \infty)$ for each $i \in I$, respectively, such that $\sum_{n=1}^{\infty} r_{n(i)}<\infty$ and $\sum_{n=1}^{\infty} s_{n(i)}<\infty$. Assume that $F=\cap_{i=1}^{k} F\left(T_{i}\right)$ is a nonempty set. Let $\left\{x_{n}\right\}$ be the multi-step iteration scheme defined by (1.14) with $\sum_{n=1}^{\infty} \gamma_{n(i)}<\infty$ for each $i \in I$. Then the iterative sequence $\left\{x_{n}\right\}$ converges strongly to a point in $F$ if and only if $\liminf \operatorname{in}_{n \rightarrow \infty} d\left(x_{n}, F\right)=0$, where $d(x, F)=\inf _{p \in F}\{d(x, p)\}$.

Proof. If $\left\{x_{n}\right\}$ converges to $p \in F$, then $\liminf _{n \rightarrow \infty} d\left(x_{n}, p\right)=0$. Since $0 \leq$ $d\left(x_{n}, F\right) \leq d\left(x_{n}, p\right)$, we have $\liminf _{n \rightarrow \infty} d\left(x_{n}, F\right)=0$.

Conversely, suppose that $\liminf _{n \rightarrow \infty} d\left(x_{n}, F\right)=0$. From (2.4), we have that

$$
d\left(x_{n+1}, p\right) \leq\left(1+B_{n(k)}\right) d\left(x_{n}, p\right)+A_{n(k)}
$$

with $\sum_{n=1}^{\infty} B_{n(k)}<\infty$ and $\sum_{n=1}^{\infty} A_{n(k)}<\infty$, which shows that the sequence $\left\{x_{n}\right\}$ is of monotone type, so $\lim _{n \rightarrow \infty} d\left(x_{n}, F\right)$ exists by Lemma 1.5. Now $\lim _{\inf } f_{n \rightarrow \infty} d\left(x_{n}, F\right)=$ 
0 reveals that $\lim _{n \rightarrow \infty} d\left(x_{n}, F\right)=0$. Now, we show that $\left\{x_{n}\right\}$ is a Cauchy sequence. Let $\varepsilon>0$. Since $\lim _{n \rightarrow \infty} d\left(x_{n}, F\right)=0$, there exists an integer $n_{0}$ such that $d\left(x_{n}, F\right)<\varepsilon / 6 Q$ and $\sum_{j=n}^{n+m-1} A_{j(k)}<\varepsilon / 4 Q$ for all $n \geq n_{0}$. So, we can find $p^{*} \in F$ such that $d\left(x_{n_{0}}, p^{*}\right)<\varepsilon / 4 Q$. Hence, for all $n \geq n_{0}$ and $m \geq 1$, we have

$$
\begin{aligned}
d\left(x_{n+m}, x_{n}\right) \leq & d\left(x_{n+m}, p^{*}\right)+d\left(x_{n}, p^{*}\right) \\
\leq & Q d\left(x_{n_{0}}, p^{*}\right)+Q \sum_{j=n_{0}}^{n+m-1} A_{j(k)} \\
& +Q d\left(x_{n_{0}}, p^{*}\right)+Q \sum_{j=n_{0}}^{n+m-1} A_{j(k)} \\
= & 2 Q\left(d\left(x_{n_{0}}, p^{*}\right)+\sum_{j=n_{0}}^{n+m-1} A_{j(k)}\right) \\
\leq & 2 Q\left(\frac{\varepsilon}{4 Q}+\frac{\varepsilon}{4 Q}\right)=\varepsilon
\end{aligned}
$$

This proves that $\left\{x_{n}\right\}$ is a Cauchy sequence. Thus, the completeness of $X$ implies that $\left\{x_{n}\right\}$ must be convergent. Assume that $\lim _{n \rightarrow \infty} x_{n}=z$. Since $C$ is closed, therefore $z \in C$. Next, we show that $z \in F$. Now, the following two inequalities:

$$
\begin{gathered}
d(z, p) \leq d\left(z, x_{n}\right)+d\left(x_{n}, p\right) \quad \forall p \in F, n \geq 1 \\
d\left(z, x_{n}\right) \leq d(z, p)+d\left(x_{n}, p\right) \quad \forall p \in F, n \geq 1
\end{gathered}
$$

give

$$
-d\left(z, x_{n}\right) \leq d(z, F)-d\left(x_{n}, F\right) \leq d\left(z, x_{n}\right), n \geq 1
$$

That is,

$$
\left|d(z, F)-d\left(x_{n}, F\right)\right| \leq d\left(z, x_{n}\right), n \geq 1 \text {. }
$$

As $\lim _{n \rightarrow \infty} x_{n}=z$ and $\lim _{n \rightarrow \infty} d\left(x_{n}, F\right)=0$, we conclude that $z \in F$, that is, $\left\{x_{n}\right\}$ converges strongly to a point in $F$. This completes the proof.

We deduce some results from Theorem 2.2 as follows.

2.3. Corollary. Let $(X, d)$ be a complete convex metric space, and let $C$ be a nonempty closed convex subset of $X$. Let $\left\{T_{i}: i \in I\right\}$ be a finite family of generalized asymptotically quasi-nonexpansive self-maps on $C$ with sequences $\left\{r_{n(i)}\right\},\left\{s_{n(i)}\right\} \subset[0, \infty)$ for each $i \in I$, respectively, such that $\sum_{n=1}^{\infty} r_{n(i)}<\infty$ 
and $\sum_{n=1}^{\infty} s_{n(i)}<\infty$. Assume that $F=\cap_{i=1}^{k} F\left(T_{i}\right)$ is a nonempty set. Let $\left\{x_{n}\right\}$ be the general iteration scheme defined by (1.14) with $\sum_{n=1}^{\infty} \gamma_{n(i)}<\infty$ for each $i \in I$. Then the sequence $\left\{x_{n}\right\}$ converges strongly to a point $p$ in $F$ if and only there exists some subsequence $\left\{x_{n_{j}}\right\}$ of $\left\{x_{n}\right\}$ which converges to a point $p \in F$.

2.4. Corollary. Let $(X, d)$ be a complete convex metric space, and let $C$ be a nonempty closed convex subset of $X$. Let $\left\{T_{i}: i \in I\right\}$ be a finite family of asymptotically quasi-nonexpansive self-maps on $C$ with sequences $\left\{r_{n(i)}\right\} \subset[0, \infty)$ for each $i \in I$, such that $\sum_{n=1}^{\infty} r_{n(i)}<\infty$. Assume that $F=\cap_{i=1}^{k} F\left(T_{i}\right)$ is a nonempty set. Let $\left\{x_{n}\right\}$ be the general iteration scheme defined by (1.14) with $\sum_{n=1}^{\infty} \gamma_{n(i)}<\infty$ for each $i \in I$. Then the sequence $\left\{x_{n}\right\}$ converges strongly to a point in $F$ if and only if $\liminf _{n \rightarrow \infty} d\left(x_{n}, F\right)=0$, where $d(x, F)=\inf _{p \in F}\{d(x, p)\}$.

Proof. Follows from Theorem 2.2 with $s_{n(i)}=0$ for each $i \in I$ and for all $n \geq 1$. This completes the proof.

2.5. Theorem. Let $(X, d)$ be a complete convex metric space, and let $C$ be a nonempty closed convex subset of $X$. Let $\left\{T_{i}: i \in I\right\}$ be a finite family of uniformly L-Lipschitzian and generalized asymptotically quasi-nonexpansive self-maps on $C$ with sequences $\left\{r_{n(i)}\right\},\left\{s_{n(i)}\right\} \subset[0, \infty)$ for each $i \in I$, respectively, such that $\sum_{n=1}^{\infty} r_{n(i)}<\infty$ and $\sum_{n=1}^{\infty} s_{n(i)}<\infty$. Assume that $F=\cap_{i=1}^{k} F\left(T_{i}\right) \neq \emptyset$. Let $\left\{x_{n}\right\}$ be the general iteration scheme defined by (1.14) with $\sum_{n=1}^{\infty} \gamma_{n(i)}<\infty$ for each $i \in I$ and $0<\delta \leq \alpha_{n(i)}<1-\delta$ for some $\delta \in\left(0, \frac{1}{2}\right)$. Then the sequence $\left\{x_{n}\right\}$ converges to $p \in F$ provided $\lim _{n \rightarrow \infty} d\left(x_{n}, T_{i} x_{n}\right)=0$, for each $i \in I$, and one member of the family $\left\{T_{i}: i \in I\right\}$ is semi-compact.

Proof. Without loss of generality, we assume that $T_{1}$ is semi-compact. Then, there exists a subsequence $\left\{x_{n_{j}}\right\}$ of $\left\{x_{n}\right\}$ such that $x_{n_{j}} \rightarrow q \in C$. Hence, for any $i \in I$, we have

$$
\begin{aligned}
d\left(q, T_{i} q\right) & \leq d\left(q, x_{n_{j}}\right)+d\left(x_{n_{j}}, T_{i} x_{n_{j}}\right)+d\left(T_{i} x_{n_{j}}, T_{i} q\right) \\
& \leq(1+L) d\left(q, x_{n_{j}}\right)+d\left(x_{n_{j}}, T_{i} x_{n_{j}}\right) \rightarrow 0 .
\end{aligned}
$$

Thus $q \in F$. By Lemma 1.5 and Theorem 2.2, $x_{n} \rightarrow q$. This completes the proof.

2.6. Theorem. Let $(X, d)$ be a complete convex metric space, and let $C$ be a nonempty closed convex subset of $X$. Let $\left\{T_{i}: i \in I\right\}$ be a finite family of uniformly L-Lipschitzian and generalized asymptotically quasi-nonexpansive self-maps on $C$ with sequences $\left\{r_{n(i)}\right\},\left\{s_{n(i)}\right\} \subset[0, \infty)$ for each $i \in I$, respectively, such that $\sum_{n=1}^{\infty} r_{n(i)}<\infty$ and $\sum_{n=1}^{\infty} s_{n(i)}<\infty$. Assume that $F=\cap_{i=1}^{r} F\left(T_{i}\right) \neq \emptyset$. Let $\left\{x_{n}\right\}$ be the general iteration scheme defined by (1.14) with $\sum_{n=1}^{\infty} \gamma_{n(i)}<\infty$ for each $i \in I$ and $0<\delta \leq \alpha_{n(i)}<1-\delta$ for some $\delta \in\left(0, \frac{1}{2}\right)$. Suppose that the mappings 
$\left\{T_{i}: i \in I\right\}$ for each $i \in I$ satisfy the following conditions:

(i) $\lim _{n \rightarrow \infty} d\left(x_{n}, T_{i} x_{n}\right)=0$ for each $i \in I$;

(ii) there exists a constant $K>0$ such that $d\left(x_{n}, T_{i} x_{n}\right) \geq K d\left(x_{n}, F\right)$, for each $i \in I$ and for all $n \geq 1$.

Then $\left\{x_{n}\right\}$ converges strongly to a point in $F$.

Proof. From conditions (i) and (ii), we have $\lim _{n \rightarrow \infty} d\left(x_{n}, F\right)=0$, it follows as in the proof of Theorem 2.2, that $\left\{x_{n}\right\}$ must converges strongly to a point in $F$. This completes the proof.

\section{Application}

In this section we give an application of Theorem 2.2.

3.1. Theorem. Let $X$ be a Banach space, and let $C$ be a nonempty closed convex subset of $X$. Let $\left\{T_{i}: i \in I\right\}$ be a finite family of generalized asymptotically quasi-nonexpansive self-maps on $C$ with sequences $\left\{r_{n(i)}\right\},\left\{s_{n(i)}\right\} \subset[0, \infty)$ for each $i \in I$, respectively, such that $\sum_{n=1}^{\infty} r_{n(i)}<\infty$ and $\sum_{n=1}^{\infty} s_{n(i)}<\infty$. Assume that $F=\cap_{i=1}^{k} F\left(T_{i}\right)$ is a nonempty set. Let $\left\{x_{n}\right\}$ be the multi-step iteration scheme defined as

$$
\begin{aligned}
x_{n+1} & =y_{n k}=\alpha_{n k} T_{k}^{n} y_{n(k-1)}+\beta_{n k} x_{n}+\gamma_{n k} u_{n k}, \\
y_{n(r-1)} & =\alpha_{n(k-1)} T_{k-1}^{n} y_{n(k-2)}+\beta_{n(k-1)} x_{n}+\gamma_{n(k-1)} u_{n(k-1)}, \\
\vdots & \\
y_{n 3} & =\alpha_{n 3} T_{3}^{n} y_{n 2}+\beta_{n 3} x_{n}+\gamma_{n 3} u_{n 3}, \\
y_{n 2} & =\alpha_{n 2} T_{2}^{n} y_{n 1}+\beta_{n 2} x_{n}+\gamma_{n 2} u_{n 2}, \\
y_{n 1} & =\alpha_{n 1} T_{1}^{n} y_{n 0}+\beta_{n 1} x_{n}+\gamma_{n 1} u_{n 1}, \quad n \geq 1,
\end{aligned}
$$

where $y_{n 0}=x_{n}$ and $\left\{u_{n 1}\right\},\left\{u_{n 2}\right\}, \ldots,\left\{u_{n k}\right\}$ are bounded sequences in $C$ with $\left\{\alpha_{n i}\right\},\left\{\beta_{n i}\right\}$, and $\left\{\gamma_{n i}\right\}$ are appropriate real sequences in $[0,1]$ such that $\alpha_{n i}+$ $\beta_{n i}+\gamma_{n i}=1$ for all $i=1,2, \ldots, k$ and all $n$ with $\sum_{n=1}^{\infty} \gamma_{n i}<\infty$ for each $i \in I$. If $\liminf _{n \rightarrow \infty} d\left(x_{n}, F\right)=0$, then the iterative sequence $\left\{x_{n}\right\}$ converges strongly to a point $p \in F$.

Proof. Since $\left\{u_{n i}, i=1,2, \ldots, k, n \geq 1\right\}$ are bounded sequences in $C$, so we can set

$$
M=\max \left\{\sup _{n \geq 1}\left\|u_{n i}-p\right\|, i=1,2, \ldots, k\right\} .
$$


Let $p \in F, r_{n}=\max \left\{r_{n(i)}: i=1,2, \ldots, k\right\}$ and $s_{n}=\max \left\{s_{n(i)}: i=\right.$ $1,2, \ldots, k\}$ for all $n$. Since $\sum_{n=1}^{\infty} r_{n(i)}<\infty$ and $\sum_{n=1}^{\infty} s_{n(i)}<\infty$, for all $i=$ $1,2, \ldots, k$, therefore $\sum_{n=1}^{\infty} r_{n}<\infty$ and $\sum_{n=1}^{\infty} s_{n}<\infty$. Then by using (3.1), we have

$$
\begin{aligned}
\left\|y_{n 1}-p\right\| & =\left\|\alpha_{n 1} T_{1}^{n} x_{n}+\beta_{n 1} x_{n}+\gamma_{n 1} u_{n 1}-p\right\| \\
& \leq \alpha_{n 1}\left\|T_{1}^{n} x_{n}-p\right\|+\beta_{n 1}\left\|x_{n}-p\right\|+\gamma_{n 1}\left\|u_{n 1}-p\right\| \\
& \leq \alpha_{n 1}\left[\left(1+r_{n 1}\right)\left\|x_{n}-p\right\|+s_{n 1}\right]+\beta_{n 1}\left\|x_{n}-p\right\|+\gamma_{n 1}\left\|u_{n 1}-p\right\| \\
& \leq\left(\alpha_{n 1}+\beta_{n 1}\right)\left(1+r_{n 1}\right)\left\|x_{n}-p\right\|+\alpha_{n 1} s_{n 1}+\gamma_{n 1}\left\|u_{n 1}-p\right\| \\
& \leq\left(\alpha_{n 1}+\beta_{n 1}\right)\left(1+r_{n}\right)\left\|x_{n}-p\right\|+\alpha_{n 1} s_{n}+\gamma_{n 1} M \\
& =\left(1-\gamma_{n 1}\right)\left(1+r_{n}\right)\left\|x_{n}-p\right\|+\alpha_{n 1} s_{n}+\gamma_{n 1} M \\
& \leq\left(1+r_{n}\right)\left\|x_{n}-p\right\|+s_{n}+\gamma_{n 1} M \\
& =\left(1+r_{n}\right)\left\|x_{n}-p\right\|+A_{n 1}
\end{aligned}
$$

where $A_{n 1}=s_{n}+\gamma_{n 1} M$, since by assumptions $\sum_{n=1}^{\infty} s_{n}<\infty$ and $\sum_{n=1}^{\infty} \gamma_{n 1}<\infty$, it follows that $\sum_{n=1}^{\infty} A_{n 1}<\infty$.

Again from (3.1) and (3.2), we obtain that

$$
\left\|y_{n 2}-p\right\| \leq\left(1+r_{n}\right)^{2}\left\|x_{n}-p\right\|+A_{n 2}
$$

where $A_{n 2}=\left(1+r_{n}\right) A_{n 1}+s_{n}+\gamma_{n 2} M$, since by assumptions $\sum_{n=1}^{\infty} s_{n}<\infty$, $\sum_{n=1}^{\infty} \gamma_{n 2}<\infty$ and $\sum_{n=1}^{\infty} A_{n 1}<\infty$, it follows that $\sum_{n=1}^{\infty} A_{n 2}<\infty$. 
Continuing the above process, using (3.1), we get

$$
\begin{aligned}
\left\|x_{n+1}-p\right\| \leq & \left\|\alpha_{n k}\left(T_{k}^{n} y_{n(k-1)}-p\right)+\beta_{n k}\left(x_{n}-p\right)+\gamma_{n k}\left(u_{n k}-p\right)\right\| \\
\leq & \alpha_{n k}\left\|T_{k}^{n} y_{n(k-1)}-p\right\|+\beta_{n k}\left\|x_{n}-p\right\|+\gamma_{n k}\left\|u_{n k}-p\right\| \\
\leq & \alpha_{n k}\left[\left(1+r_{n k}\right)\left\|y_{n(k-1)}-p\right\|+s_{n k}\right]+\beta_{n k}\left\|x_{n}-p\right\| \\
& +\gamma_{n k}\left\|u_{n k}-p\right\| \\
\leq & \alpha_{n k}\left[\left(1+r_{n}\right)\left\|y_{n(k-1)}-p\right\|+s_{n}\right]+\beta_{n k}\left\|x_{n}-p\right\| \\
& +\gamma_{n k}\left\|u_{n k}-p\right\| \\
\leq & \alpha_{n k}\left(1+r_{n}\right)\left\|y_{n(k-1)}-p\right\|+\alpha_{n k} s_{n}+\beta_{n k}\left\|x_{n}-p\right\| \\
& +\gamma_{n k}\left\|u_{n k}-p\right\| \\
\leq & \alpha_{n k}\left(1+r_{n}\right)\left[\left(1+r_{n}\right)^{k-1}\left\|x_{n}-p\right\|+A_{n(k-1)}\right]+\alpha_{n k} s_{n} \\
& +\beta_{n k}\left\|x_{n}-p\right\|+\gamma_{n k}\left\|u_{n k}-p\right\| \\
\leq & \left(\alpha_{n k}+\beta_{n k}\right)\left(1+r_{n}\right)^{k}\left\|x_{n}-p\right\|+\alpha_{n k}\left(1+r_{n}\right) A_{n(k-1)} \\
& +\alpha_{n k} s_{n}+\gamma_{n k} M \\
= & \left(1-\gamma_{n k}\right)\left(1+r_{n}\right)^{k}\left\|x_{n}-p\right\|+\alpha_{n k}\left(1+r_{n}\right) A_{n(k-1)} \\
& +\alpha_{n k} s_{n}+\gamma_{n k} M \\
\leq & \left(1+r_{n}\right)^{k}\left\|x_{n}-p\right\|+\left(1+r_{n}\right) A_{n(k-1)}+s_{n}+\gamma_{n k} M \\
= & \left(1+r_{n}\right)^{k}\left\|x_{n}-p\right\|+A_{n k}
\end{aligned}
$$

where $A_{n k}=\left(1+r_{n}\right) A_{n(k-1)}+s_{n}+\gamma_{n k} M$, since by assumptions $\sum_{n=1}^{\infty} r_{n}<$ $\infty, \sum_{n=1}^{\infty} s_{n}<\infty, \sum_{n=1}^{\infty} \gamma_{n k}<\infty$ and $\sum_{n=1}^{\infty} A_{n(k-1)}<\infty$, it follows that $\sum_{n=1}^{\infty} A_{n k}<\infty$. Therefore, by our assumptions, we know that the sequence $\left\{x_{n}\right\}$ is of monotone type and so the conclusion follows from Theorem 2.2. This completes the proof.

3.2. Remark. (1) If $\gamma_{n(i)}=0$ for each $i \in I$ and for all $n \geq 1$, then the approximation results about

(i) modified Mann iterations in [16] in Hilbert spaces,

(ii) modified Mann iterations in [17] in uniformly convex Banach spaces,

(iii) modified Ishikawa iterations in Banach spaces [4, 9, 11], and

(iv) the three-step iteration scheme in uniformly convex Banach spaces from $[7,20]$ are immediate consequences of our results.

(2) The approximation results about

(i) modified Ishikawa iterations with errors in Banach spaces [12], and 
(ii) the two-step and three-step iteration scheme with errors in uniformly convex Banach spaces from $[13,15]$ are immediate consequences of our results.

(3) Our results also extend the results of Khan et al. [8] to the case of more general class of asymptotically quasi-nonexpansive mappings and iteration scheme with errors consider in this paper.

(4) Our results also generalize the results of [6] in the setup of convex metric spaces.

(5) Our results also extend the corresponding results of $[2,10]$ to the case of more general class of asymptotically nonexpansive and asymptotically nonexpansive type mappings and multi-step iteration scheme with errors considered in this paper.

3.3. Remark. Every uniformly convex Banach spaces are uniformly convex metric spaces as shown in the following example:

3.4. Example. Let $H$ be a Hilbert space and let $X$ be a nonempty closed subset of $\{x \in H:\|x\|=1\}$ such that if $x, y \in X$ and $\alpha, \beta \in[0,1]$ with $\alpha+\beta=1$, then $(\alpha x+\beta y) /\|\alpha x+\beta y\| \in X$ and $\delta(X) \leq \sqrt{2} / 2$; see [14], where $\delta$ is a modulus of convexity of $X$. Let $d(x, y)=\cos ^{-1}\{(x, y)\}$ for every $x, y \in X$, where (.,.) is the inner product of $H$. When we define a convex structure $W$ for $(X, d)$ properly, it is easily seen that $(X, d)$ becomes a complete and uniformly convex metric space.

Also, the following example shows that the generalized asymptotically quasinonexpansive mappings includes the class of asymptotically quasi-nonexpansive mappings:

3.5. Example. Let $E$ be the real line with the usual metric and $K=[0,1]$. Define $T: K \rightarrow K$ by

$$
T(x)=\left\{\begin{array}{cl}
\mathrm{x} / 2, & \text { if } x \neq 0 \\
0, & \text { if } x=0 .
\end{array}\right.
$$

Obviously $T(0)=0$, i.e., 0 is a fixed point of the mapping $T$. Thus, $T$ is quasinonexpansive. It follows that $T$ is uniformly quasi-1 Lipschitzian and asymptotically quasi-nonexpansive with the constant sequence $\left\{k_{n}\right\}=\{1\}$ for each $n \geq 1$ and hence it is generalized asymptotically quasi-nonexpansive mapping with constant sequences $\left\{k_{n}\right\}=\{1\}$ and $\left\{s_{n}\right\}=\{0\}$ for each $n \geq 1$ but the converse is not true in general.

\section{Conclusion.}

According to the Examples 3.4 and 3.5, we come to a conclusion that if the results are true in uniformly convex Banach spaces then the results are also true 
in complete convex metric spaces. Thus our results are good improvement and generalization of corresponding results of $[2,4,6,7,9,11,12,15,16,17,20]$.

Acknowledgement. The author thank the referees for their valuable suggestions and comments on the manuscript.

\section{References}

[1] S.S. Chang, Y.J. Cho and H.Y. Zhou, Iterative methods for nonlinear operator equations in Banach spaces, Nova Science Publishers, New York (2002).

[2] S.S. Chang, J.K. Kim and D.S. Jin, Iterative sequences with errors for asymptotically quasi-nonexpansive type mappings in convex metric spaces, Archives of Inequality and Applications 2(2004), 365-374.

[3] C.E. Chidume, Convergence theorems for asymptotically pseudocontractive mappings, Nonlinear Anal. 49(2002), no.1, 1-11.

[4] H. Fukhur-ud-din and S.H. Khan, Convergence of iterates with errors of asymptotically quasi-nonexpansive mappings and applications, J. Math. Anal. Appl. 328(2007), 821-829.

[5] K. Goebel and W.A. Kirk, A fixed point theorem for asymptotically nonexpansive mappings, Proc. Amer. Math. Soc. 35(1972), 171-174.

[6] S. Imnang and S. Suantai, Common fixed points of multi-step Noor iterations with errors for a finite family of generalized asymptotically quasi-nonexpansive mappings, Abstr. Appl. Anal. (2009), Article ID 728510, 14pp.

[7] A.R. Khan, A.A. Domlo and H. Fukhar-ud-din, Common fixed points of Noor iteration for a finite family of asymptotically quasi-nonexpansive mappings in Banach spaces, J. Math. Anal. Appl. 341(2008), 1-11.

[8] A.R. Khan, M.A. Khamsi and H. Fukhar-ud-din, Strong convergence of a general iteration scheme in CAT(0) spaces, Nonlinear Anal.: TMA, 74(2011), no.3, 783-791.

[9] S.H. Khan and W. Takahashi, Approximating common fixed points of two asymptotically nonexpansive mappings, Sci. Math. Jpn. 53(2001), no. 1, 143148.

[10] J.K. Kim, K.H. Kim and K.S. Kim, Three-step iterative sequences with errors for asymptotically quasi-nonexpansive mappings in convex metric spaces, Nonlinear Anal. Convex Anal. RIMS Vol. 1365(2004), pp. 156-165.

[11] Q.H. Liu, Iterative sequences for asymptotically quasi-nonexpansive mappings, J. Math. Anal. Appl. 259(2001), 1-7.

[12] Q.H. Liu, Iterative sequences for asymptotically quasi-nonexpansive mappings with error member, J. Math. Anal. Appl. 259(2001), 18-24.

[13] Q.H. Liu, Iterative sequences for asymptotically quasi-nonexpansive mappings with error member of uniformly convex Banach spaces, J. Math. Anal. Appl. 266(2002), 468-471.

[14] H.V. Machado, Fixed point theorems for nonexpansive mappings in metric spaces with normal structure, Thesis, The University of Chicago, 1971.

[15] G.S. Saluja, Approximating fixed points of Noor iteration with errors for asymptotically quasi-nonexpansive mappings, Funct. Anal. Appr. Comput. 1(2009), no.1, 31-48. 
[16] J. Schu, Iterative construction of fixed points of asymptotically nonexpansive mappings, J. Math. Anal. Appl. 158(1991), 407-413.

[17] J. Schu, Weak and strong convergence to fixed points of asymptotically nonexpansive mappings, Bull. Austral. Math. Soc. 43(1991), no.1, 153-159.

[18] W. Takahashi, A convexity in metric space and nonexpansive mappings I, Kodai Math. Sem. Rep. 22(1970), 142-149.

[19] K.K. Tan and H.K. Xu, Approximating fixed points of nonexpansive mappings by the Ishikawa iteration process, J. Math. Anal. Appl. 178(1993), 301-308.

[20] B.L. Xu and M.A. Noor, Fixed point iterations for asymptotically nonexpansive mappings in Banach spaces, J. Math. Anal. Appl. 267(2002), no.2, 444453.

[21] Y. Xu, Ishikawa and Mann iterative processes with errors for nonlinear strongly accretive operator equation, J. Math. Anal. Appl. 224(1998), no.1, 91-101.

[22] H. Zhou, J.I. Kang, S.M. Kang and Y.J. Cho, Convergence theorems for uniformly quasi-Lipschitzian mappings, Int. J. Math. Math. Sci. 15(2004), 763775 . 
